\title{
Mối quan hệ giữa thương hiệu tổ chức và thương hiệu cá nhân trong lĩnh vụ̣c báo chí: Trường hợp tại Việt Nam
}

\section{The relationship between corporate brand and personal brand in the press: The case study in Vietnam}

\author{
Tô Đình Tuân ${ }^{1 *}$, Nguyễn Minh Hà2 \\ ${ }^{1}$ Ban Tuyên giáo Thành ủy Thành phố Hồ Chí Minh, Việt Nam \\ ${ }^{2}$ Trường Đại học Mở Thành Phố Hồ Chí Minh, Việt Nam \\ *Tác giả liên hệ, Email: todinhtuan@gmail.com
}

\begin{tabular}{|c|c|}
\hline THÔNG TIN & TÓM TÁT \\
\hline $\begin{array}{l}\text { DOI:10.46223/HCMCOUJS. } \\
\text { econ.vi.13.2.509.2018 }\end{array}$ & $\begin{array}{l}\text { Nghiên cứu nhằm phân tích mối quan hệ giữa thương hiệu } \\
\text { tổ chức và thương hiệu cá nhân trong lĩnh vực báo chí. Với số } \\
\text { lượng khảo sát } 520 \text { nhà báo và sử dụng các kỹ thuật phân tích } \\
\text { thống kê, phân tích Cronbach's Alpha, EFA và SEM, kết quả } \\
\text { nghiên cứu cho thấy i) Tên cơ quan báo chí có ảnh hưởng dương } \\
\text { đến Hình ảnh cơ quan báo chí và danh tiếng của cơ quan báo chí; }\end{array}$ \\
\hline Ngày nhận: 23/03/2018 & ii) Hình ảnh cơ quan báo chí có ảnh hưởng dương đến danh tiếng \\
\hline Ngày nhận lại: 22/04/2018 & cơ quan báo chí và Sự cam kết/lòng trung thành của cơ quan báo \\
\hline Duyệt đăng: 04/05/2018 & $\begin{array}{l}\text { chí; iii) Danh tiếng của cơ quan báo chí có ảnh hưởng dương đến } \\
\text { Thương hiệu cá nhân của những nhà báo và Sự cam kêt/lòng } \\
\text { trung thành với nhân viên của cơ quan báo chí; iv) Sự cam } \\
\text { kêt/llòng trung thành của cơ quan báo chí ảnh hưởng dương đến } \\
\text { thương hiệu cá nhân của nhà báo. Tuy nhiên, nghiên cứu cho thây }\end{array}$ \\
\hline $\begin{array}{l}\text { Tùu khóa: } \\
\text { báo chí, nhà báo, thương } \\
\text { hiệu cá nhân, thương hiệu tổ } \\
\text { chức }\end{array}$ & $\begin{array}{l}\text { Tên cơ quan báo chí không ảnh hưởng đến thương hiệu cá nhân } \\
\text { của những nhà báo và Sự cam kết/lòng trung thành của cơ quan } \\
\text { báo chí; Hình ảnh cơ quan báo chí không ảnh hưởng đến Thương } \\
\text { hiệu cá nhân của các nhà báo. }\end{array}$ \\
\hline
\end{tabular}

\begin{abstract}
The study investigates the relationship between the corporate brand and personal brand in the press in Vietnam. 520 journalists and reporters were surveyed and the analysis of statistics, Cronbach Alpha, EFA and SEM were applied to the study, the results show that i) the name of press corporate positively influences the press corporate's image and reputation, ii) the press corporate's image strongly affects the press corporate's reputation and commitment; iii) the press corporate's reputation has a positive impact on journalists' personal brands
\end{abstract} Keywords:

press, journalist, personal brand, corporate brand 
and the press corporate's commitment; iv) the press corporate's commitment deeply influences journalists' personal brands. However, the study demonstrates that the name of press corporate does not affect journalists' personal brands and the press corporate's commitment; the press corporate's image does not influence journalists' personal brands.

\section{Giới thiệu}

Theo Bộ Thông tin và Truyền thông, hiện nay tại Việt Nam có 860 tờ báo, tạp chí in (200 báo, 660 tạp chí), 135 báo, tạp chí điện tử (112 báo, tạp chí điện tử của cơ quan báo in và 23 báo, tạp chí điện tử độc lập, ngoài ra còn có 258 trang thông tin điện tử tổng hợp của các cơ quan báo chí được cấp phép), 67 đài phát thanh, truyền hình. Tổng cộng có 950 cơ quan báo chí, hơn 18.000 người được cấp thẻ nhà báo.

Theo Holton và Molyneux (2015), thương hiệu - đặc biệt là thương hiệu báo chí là vấn đề đã và đang thu hút sự chú ý, quan tâm của giới chuyên môn, các nhà nghiên cứu. Trong bối cảnh sự cạnh tranh thông tin ngày càng khốc liệt, công nghệ phát triển như vũ bão trong những năm gần đây, việc nghiên cứu về thương hiệu nói chung, thương hiệu trong lĩnh vực báo chí nói riêng ngày càng trở nên bức thiết.

Việc nghiên cứu về thương hiệu trong lĩnh vực báo chí tại Việt Nam là một đòi hỏi cấp thiết (Do, 2013). Tuy nhiên, theo sự hiểu biết của người nghiên cứu, đến thời điểm hiện nay tại Việt Nam chưa tìm thấy nghiên cứu khoa học nào về thương hiệu trong lĩnh vực báo chí. Do đó, sự hiểu biết về thương hiệu trong lĩnh vực báo chí còn khá mơ hồ, cách hiểu và sự ứng dụng lý thuyết vào thực tiễn có sự khác biệt. Vì vậy, tiềm năng to lớn của thương hiệu trong lĩnh vực báo chí chưa được phát huy.

Việc nghiên cứu thành công mối quan hệ giữa thương hiệu tổ chức và thương hiệu cá nhân sẽ cung cấp cho các nhà nghiên cứu khoa học về báo chí và những người đã, đang, sẽ làm công tác báo chí một cơ sở lý thuyết vững chắc để có sự hiểu biết sâu sắc về thương hiệu báo chí. Từ đó, các nhà nghiên cứu về báo chí sẽ có nhiều công trình nghiên cứu về thương hiệu báo chí cũng như về mối quan hệ giữa Thương hiệu tổ chức và Thương hiệu cá nhân nhà báo. Bên cạnh đó, kết quả nghiên cứu về mối quan hệ giữa Thương hiệu tổ chức và Thương hiệu cá nhân nhà báo sẽ cung cấp cho lãnh đạo, quản lý các cơ quan báo chí cơ sở khoa học đáng tin cậy để họ có thể ứng dụng vào thực tế tại đơn vị, phát triển thương hiệu tổ chức của họ. Ngoài ra, các nhà báo có mong muốn xây dựng thương hiệu cá nhân cũng sẽ có một cơ sở khoa học để ứng dụng vào thực tiễn, từng bước phát triển và duy trì thương hiệu cá nhân của mình.

Từ những yêu cầu đó, nghiên cứu đi sâu phân tích mối quan hệ giữa thương hiệu tổ chức và thương hiệu cá nhân trong lĩnh vực báo chí. Căn cứ vào kết quả nghiên cứu và tình hình thực tế, nghiên cứu cũng sẽ đề xuất một số giải pháp nhằm làm tăng giá trị thương hiệu tổ chức và thương hiệu cá nhân trong lĩnh vực báo chí. 


\section{Cơ sở lý thuyết và mô hình nghiên cứu đề xuất}

\subsection{Cơ sở lý thuyết}

Thương hiệu: Fournier (1998) cho rằng, thương hiệu là nhận thức, tình cảm và niềm tin của khách hàng, đối tác về tất cả các yếu tố của tổ chức.

Thương hiệu tổ chưc: Souiden, Kassim, và Heung-Ja (2006) định nghĩa thương hiệu tổ chức là những gì nổi bật nhất, tạo dấu ấn sâu đậm nhất của tổ chức đó đối với khách hàng, đối tác và công chúng; thương hiệu tổ chức bao gồm: Tên tổ chức, Hình ảnh tổ chức, Danh tiếng tổ chức và Sự cam kết/lòng trung thành của tổ chức đối với khách hàng, nhân viên và mục tiêu phát triển thị trường, đảm bảo chất lượng sản phẩm.

Thương hiệu cá nhân: Theo Schawbel (2010), thương hiệu cá nhân là hình ảnh, giá trị bản thân của một cá nhân giúp người khác phân biệt được cá nhân đó với mọi người xung quanh. Thương hiệu cá nhân chính là hình ảnh của một con người trước công chúng, cộng đồng, có thể đo lường được thông qua các tiêu chí được xếp theo thứ tự: (i) Mức độ được biết đến; (ii) Những giá trị, thành tích hay phẩm chất; (iii) Mức độ ảnh hưởng với công chúng.

\section{Mối quan hệ giữa các thành phần của thương hiệu tổ chức và thương hiệu cá nhân}

Từ định nghĩa của Souiden và cộng sự (2006), Thương hiệu tổ chức có 4 thành phần: Tên tổ chức, Hình ảnh tổ chức, Danh tiếng tổ chức và Sự cam kết của tổ chức. Do đó, nghiên cứu sẽ phân tích từng thành phần của Thương hiệu tổ chức đều tác động với nhau và mỗi thành phần của Thương hiệu tổ chức đều tác động đến Thương hiệu cá nhân.

\section{nhân}

Tên tổ chức đối với các thành phần khác của thương hiệu tổ chức và thương hiệu cá

Mỗi con người, mỗi đồ vật, tổ chức...đều có tên. Tên là cách để người ta gọi và hiểu đúng về đối tượng đó. Tên tổ chức trước tiên có tác dụng xác định một thương hiệu và tạo điều kiện cho định hình vị trí thương hiệu. Tên tổ chức là cách rõ ràng nhất để phân biệt với những thương hiệu khác (Hankinson \& Cowking, 1993).

Tên của một tổ chức còn là biểu tượng của tổ chức, tượng trưng cho quyền sở hữu, giúp mọi người đưa ra quyết định mua hàng, hợp tác, làm việc với tổ chức đó nhanh hơn. Ngoài ra, tên tổ chức đảm bảo với khách hàng rằng các tính năng, chức năng và đặc điểm của thương hiệu được thể hiện trên các sản phẩm của tổ chức đó, nó sẽ không thay đổi theo thời gian. Tên tổ chức có ảnh hưởng trực tiếp đến thương hiệu cá nhân của người tiêu dùng, các đối tác và những người thuộc tổ chức đó. Người tiêu dùng, các đối tác cảm thấy an tâm, tự tin, thậm chí là có phong cách, đẳng cấp, có thương hiệu khi sử dụng hàng hóa hoặc làm việc, hợp tác với các tổ chức có tên quen thuộc, nổi tiếng như Sony, Toyota, Sanyo, Samsung, Hyundai, Apple, Google, ... Nhân viên làm việc trong các tổ chức có tên tuổi, nổi tiếng, uy tín cũng cho biết thương hiệu cá nhân của họ được nâng cao và đảm bảo hơn so với các nhân viên đang làm việc trong các tổ chức ít nổi tiếng khác (Hankinson \& Cowking, 1993).

Theo Souiden và cộng sự (2006), tên của tổ chức tác động đến hình ảnh tổ chức. Thông thường, ngay khi nghe tên của một tổ chức nào đó, trong não bộ mỗi người sẽ xuất hiện hình ảnh bao quát về tổ chức đó. Hình ảnh xuất hiện có thể tích cực hoặc tiêu cực tùy thuộc vào việc 
xây dựng hình ảnh của tổ chức đó và quan điểm, góc nhìn, sự cảm nhận của mỗi người. Tên của tổ chức luôn tạo ấn tượng đầu tiên nên rất quan trọng đối với khách hàng, đối tác. Ấn tượng tốt thường tạo cho họ cảm giác tốt về tổ chức đó hoặc ngược lại.

Việc đặt tên cho tổ chức phải hướng đến việc góp phần xây dựng một hình ảnh tổ chức tích cực, tạo cảm giác an tâm, lạc quan cho các đối tác, khách hàng nhưng nên gắn liền với lĩnh vực đang hoạt động; không thể hiện quá những khả năng mà tổ chức đó có thể đáp ứng. Việc đặt tên cho tổ chức cũng có thể thay đổi theo thời gian, tùy thuộc vào điều kiện, thực tế hoạt động. Sau một thời gian hoạt động, có không ít tổ chức buộc phải thay đổi tên để xác định lại hình ảnh tổ chức của mình. Khi một tổ chức cần phá vỡ hình ảnh quá khứ và thiết lập một hình ảnh mới, việc thay đổi tên tổ chức có thể giúp họ thay đổi một phần nào đó hình ảnh cũ của tổ chức (Gregory \& Wiechmann, 1999).

Theo Schawbel (2010), tên của tổ chức có tác động đến danh tiếng của tổ chức đó. Tên tổ chức là yếu tố đầu tiên, quan trọng nhất để mọi người đánh giá về danh tiếng của tổ chức đó. Ở góc độ ngược lại, danh tiếng của tổ chức khẳng định giá trị đối với tên của tổ chức.

Souiden và cộng sự (2006) cho rằng tên của tổ chức có tác động đến lòng trung thành với tổ chức của người tiêu dùng và các cá nhân đang làm việc, cống hiến cho tổ chức đó. Người tiêu dùng thường có lòng trung thành với những sản phẩm có cái tên quen thuộc, nổi tiếng, uy tín. Những tổ chức có tên nổi tiếng, là "thương hiệu lớn" thường có sự cam kết/lòng trung thành với mục tiêu phát triển đã đề ra; luôn đảm bảo quyền lợi cho nhân viên, sã̃n sàng hỗ trợ nhân viên nếu họ bị tai nạn trong quá trình thực hiện nhiệm vụ được tổ chức giao.

Từ những lý luận trên, nghiên cứu đề xuất một số giả thuyết như sau:

H1: Tên tổ chức có tác động dương đến thuơng hiệu cá nhân của nhũng nguời đang làm việc tại tổ chức

H2: Tên tổ chức có tác động dương đến hình ảnh của tổ chức

H3. Tên tổ chức có tác động dưong đến danh tiếng của tổ chức

H4. Tên tổ chức có tác động dương đến sự cam kết của tổ chức đó đối với quyền lợi của nhân viên

\section{Hình ảnh tổ chức đối với các thành phần của thưong hiệu tổ chức và thương hiệu cá nhân}

Hình ảnh tổ chức là những hình ảnh gắn liền với bản chất của tổ chức; giúp mọi người hình dung một cách nhanh chóng, trực quan nhất về một tổ chức. Hình ảnh tổ chức gắn liền với tên của một tổ chức. Theo Kennedy (1977), hình ảnh tổ chức luôn đóng một vai trò quan trọng trong quá trình xây dựng và phát triển của tổ chức. Hình ảnh tổ chức là một tài sản có giá trị mà tổ chức cần phải quản lý (Abratt \& Mofokeng, 2001). Hatch và Schultz (2003) cũng cho rằng, hình ảnh tổ chức có vai trò hết sức quan trọng đối với sự tồn tại và phát triển của tổ chức. Nếu hình ảnh tổ chức tích cực sẽ tạo thuận lợi cho tổ chức đó. Ngược lại, nếu hình ảnh tổ chức tiêu cực sẽ gây khó khăn cho tổ chức. Đối với một doanh nghiệp, việc có một hình ảnh tốt, tích cực có thể ảnh hưởng đến doanh số bán hàng và thị trường cổ phiếu của doanh nghiệp đó 
(Shapiro,1983). Do đó, bất cứ tổ chức nào cũng cần duy trì một hình ảnh tích cực trong lòng mọi người.

Hsieh (2002) kết luận rằng hình ảnh tổ chức có thể ảnh hưởng đến hành vi của người tiêu dùng hoặc đối tác. Hình ảnh tổ chức là một yếu tố quan trọng ảnh hưởng đến nhận thức về chất lượng, đánh giá của người tiêu dùng về sự hài lòng và lòng trung thành của khách hàng; tác động đến thương hiệu cá nhân của người tiêu dùng và những nhân viên đang làm việc tại tổ chức đó. Một số nhà nghiên cứu khẳng định rằng hình ảnh tổ chức có khả năng tạo nên uy tín của tổ chức. Một hình ảnh tổ chức tích cực, tốt đẹp sẽ dẫn đến việc hình thành danh tiếng của tổ chức trong tâm trí của công chúng. Nói cách khác, danh tiếng của tổ chức được hình thành qua thời gian bởi những ấn tượng lặp đi lặp lại của hình ảnh tổ chức.

Bhattacharya và Sen (2003) cho rằng một tổ chức có hình ảnh tích cực, tốt đẹp sẽ khiến cho nhân viên gắn bó, trung thành hơn với tổ chức đó. Nhưng đồng thời, hình ảnh của tổ chức cũng được tác động bởi sự cam kết/lòng trung thành của tổ chức đối với mục tiêu phát triển và đảm bảo quyền lợi của nhân viên. Tổ chức nào luôn đảm bảo sự cam kết/lòng trung thành với mục tiêu phát triển và bảo vệ quyền lợi cho nhân viên, hỗ trợ họ khi gặp tai nạn trong lúc thực hiện nhiệm vụ của tổ chức thì hình ảnh tổ chức đó thường tốt đẹp, tích cực hoặc ngược lại.

Từ những phân tích trên, nghiên cứu đề xuất một số giả thuyết như sau:

H5: Hình ảnh tổ chức có tác động dương đến thương hiệu cá nhân của nhũng người đang làm việc tại tổ chức

H6: Hình ảnh tổ chức có tác động dương đến danh tiếng của tổ chức

H7: Hình ảnh tổ chức có tác động dương đến sụ cam kết của tổ chức đối với quyền lợi của nhân viên

\section{Danh tiếng của tổ chức đối với các thành phần của thương hiệu tổ chức và thuơng hiệu cá nhân}

Theo Druckenmiller (2004), lãnh đạo nhiều tổ chức ngày càng nhận ra tầm quan trọng của danh tiếng tổ chức bởi danh tiếng tổ chức có tác động tích cực để đạt được mục tiêu kinh doanh và duy trì sự cạnh tranh. Trong những năm gần đây, nhiều tổ chức lớn và có thương hiệu đã học được những bài học cay đắng về sự giảm sút uy tín của họ đã gây hại cho nhân viên và làm giảm lòng trung thành của khách hàng, đe dọa tài chính và cả sự sống còn của tổ chức. Trong nhiều năm qua, sự giám sát công khai của công chúng ngày càng cao; sự phổ biến rộng rãi của các phương tiện truyền thông, nhu cầu của các nhà đầu tư là tăng tính minh bạch và trách nhiệm xã hội ngày càng được quan tâm. Tất cả những điều đó khiến các tổ chức ngày càng quan tâm đến việc tạo ra, duy trì và phát triển danh tiếng tổ chức. Việc phát triển thương hiệu của tổ chức có liên quan đến danh tiếng của tổ chức. Nói cách khác, Danh tiếng tổ chức có sự tác động mạnh mẽ đến thương hiệu tổ chức và thương hiệu cá nhân của những người làm việc cho tổ chức đó.

Gotsi và Wilson (2001) kết luận rằng, có một mối quan hệ qua lại, tác động lẫn nhau giữa Danh tiếng tổ chức và Hình ảnh tổ chức. 
Theo Souiden và cộng sự (2006), Danh tiếng tổ chức có ảnh hưởng đáng kể đến lòng trung thành của tổ chức. Danh tiếng tổ chức cũng là một trung gian hòa giải về ảnh hưởng của Hình ảnh tổ chức đối với việc đánh giá sản phẩm, chất lượng công việc của người tiêu dùng hoặc đối tác đối với tổ chức đó.

Theo Saraniemi, Juntunen, Niemelä, và Tähtinen (2010), danh tiếng của tổ chức được củng cố thông qua cách điều hành tổ chức của những người quản lý. Tất cả mọi người trong một tổ chức đều có thể ảnh hưởng đến danh tiếng của tổ chức, có thể là tích cực hoặc tiêu cực. Để giữ gìn danh tiếng của tổ chức, những người trong bộ máy cần thực hiện tốt những gì đã hứa, làm việc với chất lượng tốt và cố gắng giải quyết sớm các vấn đề mới phát sinh. Một tổ chức có danh tiếng tốt sẽ dễ dàng hơn khi xây dựng một thương hiệu tổ chức tốt; nhờ đó, các nhân viên làm việc trong tổ chức đó cũng sẽ được "thơm lây", giá trị thương hiệu cá nhân của mỗi người sẽ tăng lên. Đó là lý do khiến nhân viên trong những tổ chức có thương hiệu hoặc đang phát triển thương hiệu phải nỗ lực làm việc, cống hiến cho tổ chức và gắn bó lâu dài với tổ chức của họ. Ngoài ra, các tổ chức có danh tiếng thường duy trì tốt sự cam kết/lòng trung thành về mục tiêu phát triển đã đề ra và đảm bảo quyền lợi cho nhân viên, hỗ trợ nhân viên khi họ gặp tai nạn, khó khăn trong lúc thực hiện nhiệm vụ của tổ chức, thậm chí lúc nhân viên đã về hưu. Những hành động này tác động vào danh tiếng tổ chức nói riêng và thương hiệu tổ chức nói chung.

Nghiên cứu đề xuất một số giả thuyết như sau:

H8: Danh tiếng của tổ chức có tác động duoong đến thuơng hiệu cá nhân của nhũng nguời đang làm việc tại tổ chức

H9: Danh tiếng của tổ chức có tác động dưong đến sụ cam kết của tổ chức đối với quyền lợi của nhân viên

\section{Sự cam kết của tổ chức đối với các thành phần của thương hiệu tổ chức và thwơng hiệu cá nhân}

Theo Saraniemi và cộng sự (2010), sự cam kết đã trở thành một mục tiêu quan trọng đối với nhiều tổ chức, nhất là trong bối cảnh cạnh tranh ngày càng khốc liệt. Mỗi tổ chức đều có sự cam kết đảm bảo quyền lợi cho nhân viên... Sự cam kết của tổ chức góp phần tạo ra uy tín, củng cố thương hiệu của tổ chức. Cũng chính sự cam kết của tổ chức đối với quyền lợi của nhân viên tác động đến thương hiệu cá nhân của những nhân viên đang làm việc trong tổ chức đó. Nếu sự cam kết của tổ chức được duy trì, đảm bảo thì giá trị thương hiệu của tổ chức và giá trị thương hiệu cá nhân của những nhân viên đang làm việc trong tổ chức đó càng tăng. Ngược lại, nếu sự cam kết của tổ chức đối với quyền lợi của nhân viên không được đảm bảo thì giá trị thương hiệu tổ chức sẽ bị sụt giảm; thương hiệu cá nhân của nhân viên bị tác động tiêu cực. Thực tế cho thấy, nhiều người không mong muốn làm việc trong một tổ chức không giữ lời hứa với khách hàng, không thực hiện đúng các cam kết về chất lượng sản phẩm, không đảm bảo quyền lợi cho nhân viên vì điều đó gây tổn hại uy tín cá nhân của họ.

Với các tổ chức luôn đảm bảo sự cam kết đối với quyền lợi của nhân viên, không chỉ tác động đến thương hiệu của những nhân viên đang làm việc trong tổ chức đó mà còn tạo dựng 
và duy trì lòng trung thành của nhân viên đối với tổ chức đó. Căn cứ trên các nhận định, đánh giá này, nghiên cứu đề ra giả thuyết sau:

H10: Sự cam kết của tổ chức đối với quyền lợi của nhân viên có tác động dương đến thuoong hiệu cá nhân

\subsection{Mô hình nghiên cúu đề xuất}

Dựa vào cơ sở lý thuyết, các nghiên cứu trước của Souiden và cộng sự (2006), Saraniemi và cộng sự (2010) và kết quả nghiên cứu định tính, mô hình nghiên cứu về mối quan hệ giữa thương hiệu tổ chức và thương hiệu cá nhân được trình bày trong Hình 1 sau:

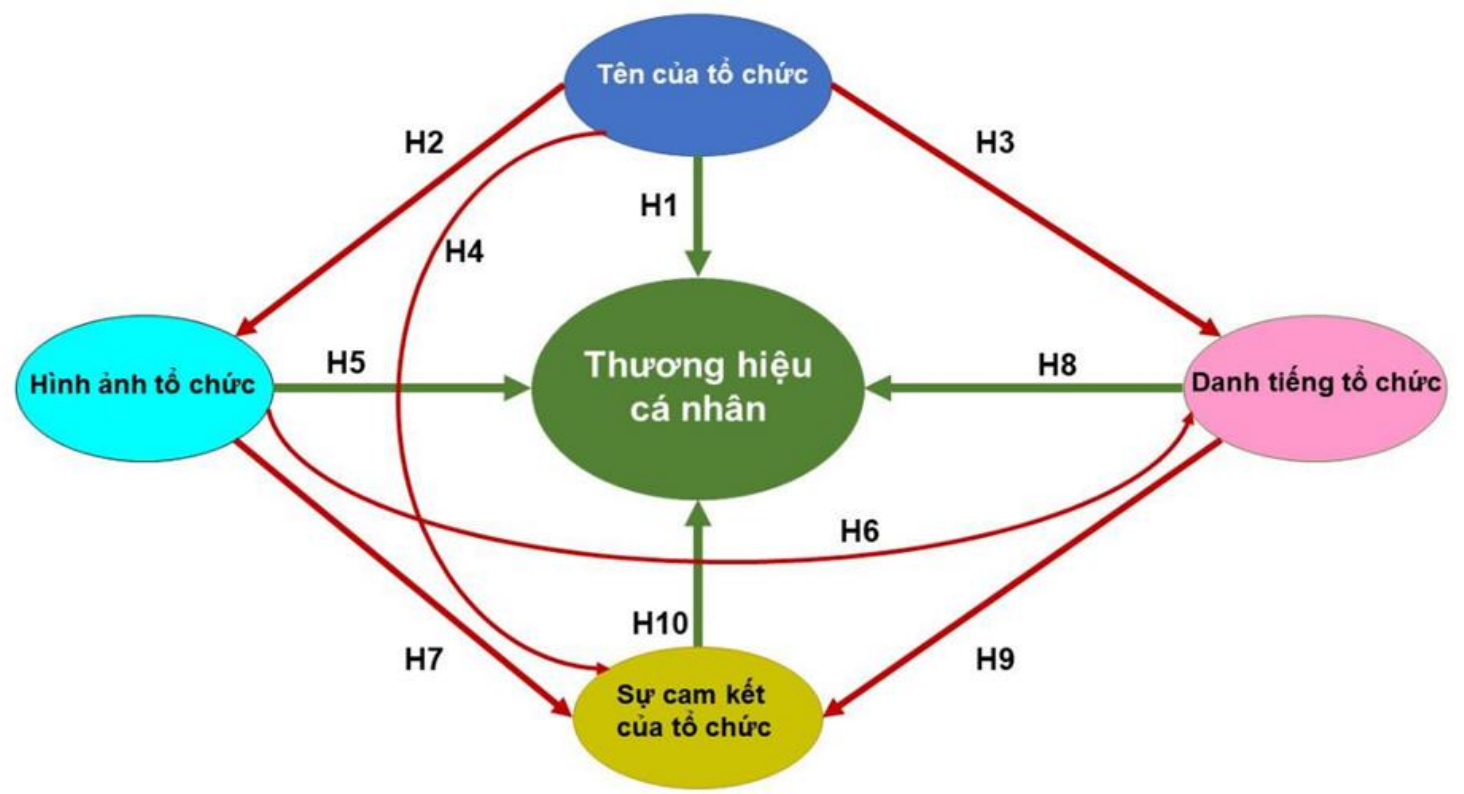

Hình 1. Mô hình nghiên cứu về mối quan hệ giữa thương hiệu tổ chức và thương hiệu cá nhân

\section{Phương pháp nghiên cứu và dữ liệu nghiên cứu}

\subsection{Phương pháp nghiên cúu}

Nghiên cứu gồm 2 bước chính: nghiên cứu định tính và nghiên cứu định lượng. Nghiên cứu định tính bằng khảo sát ý kiến chuyên gia để bổ sung và hiệu chỉnh thang đo. Phỏng vấn trực tiếp mặt đối mặt 10 nhà báo đang công tác tại các báo trung ương và Thành phố Hồ Chí Minh nhằm trao đổi chi tiết về các nội dung cần nghiên cứu cũng như các thang đo trong nghiên cứu.

Sau khi thực hiện nghiên cứu định tính để hoàn thiện thang đo, nghiên cứu tiến hành phân tích định lượng, phân tích SEM (Mô hình cấu trúc) để xác định các yếu tố tác động đến thương hiệu tổ chức, các yếu tố tác động đến thương hiệu cá nhân và mối quan hệ giữa thương hiệu tổ chức và thương hiệu cá nhân trong lĩnh vực báo chí. 
Nghiên cứu này sử dụng Thang đo Likert 5 , với: 1 . Hoàn toàn không đồng ý; 2 . Không đồng ý; 3. Bình thường; 4. Đồng ý; 5. Rất đồng ý. Thang đo chính thức bao gồm 39 biến quan sát.

\subsection{Dũ liệu nghiên cúu}

Nghiên cứu thực hiện lấy mẫu bằng phương pháp phi xác suất (phương pháp thuận tiện). Dữ liệu nghiên cứu được thu thập bằng cách phỏng vấn trực tiếp, gửi bảng câu hỏi trực tiếp cho 520 nhà báo; Số lượng phiếu thu về là 515 , đạt tỷ lệ là $99,04 \%$ so với phiếu phát ra; Số lượng phiếu hợp lệ là 508 , chiếm $98,64 \%$ số lượng phiếu thu về.

Toàn bộ dữ liệu thu thập được xử lý bằng phần mềm SPSS, AMOS, kiểm định thang đo, phân tích nhân tố khám phá (EFA) và SEM.

\section{Kết quả nghiên cứu}

\subsection{Phân tích thống kê mẫu theo các đặc tính}

Về tuổi tác, trong 508 nhà báo được khảo sát, lứa tuổi 31- 40 chiếm tỷ lệ cao nhất với 42,91\%; lứa tuổi 51- 60 chiếm tỷ lệ thấp nhất với $6,1 \%$. Về giới tính, tỷ lệ nhà báo nam chiếm $53,54 \%$; tỷ lệ nhà báo nữ chiếm 46,46\%. Về tình trạng hôn nhân, tỷ lệ nhà báo đã lập gia đình là $71,85 \%, 117$ người độc thân $(23,03 \%)$ và 26 người ly thân, ly hôn $(5,12 \%)$. Về quê quán, các nhà báo có quê quán ở miền Nam nhiều nhất (chiếm 38,38\%), kế đến là miền Trung $(35,27 \%)$, ít nhất là miền Bắc $(26,38 \%)$. Về vị trí công việc, trong số 508 nhà báo được khảo sát, có 231 nhà báo đang thực hiện vai trò phóng viên (chiếm 45,47\%), 150 nhà báo là biên tập viên (chiếm 29,53\%), 94 nhà báo là cán bộ quản lý, lãnh đạo $(18,5 \%)$ và 33 người đang giữ những vai trò, vị trí công việc khác $(6,5 \%)$. Về trình độ học vấn, số lượng nhà báo được đào tạo đại học chiếm tỷ lệ cao nhất với $85,83 \%$; trên đại học là 62 người $(0,27 \%)$ và cao đẳng 10 người $(1,97 \%)$. Về đào tạo chuyên ngành báo chí, trong tổng số 508 nhà báo được khảo sát, có 325 nhà báo được đào tạo chuyên ngành báo chí (chiếm 63,97\%); 183 nhà báo không được đào tạo chuyên ngành báo chí (chiếm $36,02 \%$ ). Về loại hình báo chí, số lượng nhà báo làm việc tại các cơ quan báo in là 227 người (chiếm 44,68\%); số nhà báo làm việc tại các đài truyền hình là 93 người (chiếm 18,31\%); số nhà báo làm việc tại đài phát thanh là 99 người (chiếm $19,49 \%$ ); số nhà báo làm việc tại các báo điện tử/trang thông tin điện tử là 89 người (chiếm 17,52\%). Về kinh nghiệm, số nhà báo có 6 -10 năm kinh nghiệm là 125 người (chiếm 24,61\%); 10 -15 năm kinh nghiệm là 101 người (chiếm 19,88\%); 16 - 20 năm kinh nghiệm là 122 người (chiếm 24,02\%); 21 - 30 năm là 80 người (chiếm $0,19 \%$ ).

\subsection{Phân tích thống kê các biến quan sát}

\section{Về Thuơng hiệu cá nhân (THCN)}




\section{Bảng 1}

Kết quả thống kê về Thương hiệu cá nhân

\begin{tabular}{|c|c|c|c|c|c|c|}
\hline Ký hiệu & Các biến quan sát & $\mathbf{N}$ & Min & Max & Mean & Std.Dev \\
\hline THCN1 & $\begin{array}{l}\text { Bạn được nhiều bạn đọc, đồng } \\
\text { nghiệp trong lĩnh vực báo chí biết } \\
\text { đến }\end{array}$ & 508 & 1.0 & 5.0 & 3.488 & .8870 \\
\hline THCN2 & $\begin{array}{l}\text { Bạn có các tác phẩm báo chí thu hút } \\
\text { sự quan tâm của bạn đọc }\end{array}$ & 508 & 1.0 & 5.0 & 3.447 & .9119 \\
\hline THCN3 & $\begin{array}{l}\text { Bạn thường được đồng nghiệp đánh } \\
\text { giá tích cực về năng lực chuyên } \\
\text { môn, nghiệp vụ báo chí }\end{array}$ & 508 & 1.0 & 5.0 & 3.748 & .6990 \\
\hline THCN4 & $\begin{array}{l}\text { Bạn được mọi người đánh giá là có } \\
\text { đạo đức nghề nghiệp }\end{array}$ & 508 & 1.0 & 5.0 & 4.138 & .7356 \\
\hline THCN5 & $\begin{array}{l}\text { Bạn được cho rằng đã đóng góp tích } \\
\text { cực cho cộng đồng }\end{array}$ & 508 & 1.0 & 5.0 & 3.799 & .7504 \\
\hline THCN6 & $\begin{array}{l}\text { Bạn được đánh giá là có khả năng } \\
\text { hợp tác tốt với đồng nghiệp trong } \\
\text { lĩnh vực báo chí }\end{array}$ & 508 & 1.0 & 5.0 & 3.992 & .6851 \\
\hline THCN7 & $\begin{array}{l}\text { Bạn thường được tham dự (đối với } \\
\text { phóng viên) để đưa tin hoặc biên tập } \\
\text { (đối với biên tập viên) hoặc duyệt } \\
\text { (đối với quản lý, lãnh đạo) các sự } \\
\text { kiện quan trọng. }\end{array}$ & 508 & 1.0 & 5.0 & 3.650 & .9184 \\
\hline THCN8 & $\begin{array}{l}\text { Bạn được nhiều bạn bè, đồng nghiệp } \\
\text { trong lĩnh vực báo chí nể phục }\end{array}$ & 508 & 1.0 & 5.0 & 3.537 & .7998 \\
\hline
\end{tabular}

Nguồn: Kết quả xử lý từ dữ liệu điều tra

Biến "Bạn được mọi người đánh giá là có đạo đức nghề nghiệp" (THCN4) được đánh giá cao nhất, với giá trị trung bình là 4.138. Biến 'Bạn có các tác phẩm báo chí thu hút sự quan tâm của bạn đọc' (THCN2) có giá trị trung bình thấp nhất là 3.447.

\section{Về Tên cơ quan (tổ chức) báo chí (TCQBC)}

\section{Bảng 2}

Kết quả thống kê về Tên cơ quan báo chí

\begin{tabular}{|c|l|c|l|l|l|l|}
\hline Ký hiệu & \multicolumn{1}{|c|}{ Các biến quan sát } & N & Min & Max & Mean & Std.Dev \\
\hline TCQBC1 & $\begin{array}{l}\text { Tên cơ quan báo chí xuất bản các } \\
\text { sản phẩm báo chí nổi tiếng/được } \\
\text { nhiều người biết đến (well known). }\end{array}$ & 508 & 1.0 & 5.0 & 4.118 & .7881 \\
\hline
\end{tabular}




\begin{tabular}{|c|l|l|l|l|l|l|}
\hline Ký hiệu & \multicolumn{1}{|c|}{ Các biến quan sát } & $\mathbf{N}$ & Min & Max & Mean & Std.Dev \\
\hline TCQBC2 & $\begin{array}{l}\text { Tên cơ quan báo chí được nhiều } \\
\text { người quan tâm. }\end{array}$ & 508 & 1.0 & 5.0 & 4.096 & .8047 \\
\hline TCQBC3 & $\begin{array}{l}\text { Sản phẩm báo chí luôn gắn liền với } \\
\text { tên cơ quan báo chí làm ra sản } \\
\text { phẩm báo chí. }\end{array}$ & 508 & 1.0 & 5.0 & 4.035 & .7343 \\
\hline TCQBC4 & $\begin{array}{l}\text { Tên cơ quan báo chí thể hiện đối } \\
\text { tượng bạn đọc chính cần quan tâm } \\
\text { (tầng lớp, giới tính, độ tuối...). }\end{array}$ & 508 & 1.0 & 5.0 & 3.872 & .8574 \\
\hline TCQBC5 & $\begin{array}{l}\text { Sản phấm báo chí vừa mang tên cơ } \\
\text { quan báo chí, vừa thể hiện loại hình } \\
\text { truyền thông (như: báo, radio, tivi; } \\
\text { nhật báo, tạp chí, tuần báo,...). }\end{array}$ & 508 & 1.0 & 5.0 & 3.843 & .8254 \\
\hline
\end{tabular}

Nguồn: Kết quả xử lý từ dữ liệu điều tra

Tên cơ quan báo chí xuất bản các sản phẩm báo chí nổi tiếng/được nhiều người biết đến (TCQBC1), với giá trị trung bình là 4.118; tuy nhiên biến 'Sản phẩm báo chí vừa mang tên cơ quan báo chí, vừa thể hiện loại hình truyền thông (như: báo, radio, tivi; nhật báo, tạp chí, tuần báo, ...)' (TCQBC5) có giá trị thấp nhất là 3.843. Nhìn chung, các biến quan sát trong yếu tố này được đánh giá tương đối cao.

Về Hình ảnh cơ quan (tổ chức) báo chí (HACQBC)

\section{Bảng 3}

Kết quả thống kê về Hình ảnh cơ quan báo chí

\begin{tabular}{|l|l|c|c|c|c|c|}
\hline Ký hiệu & Các biến quan sát & $\mathbf{N}$ & Min & Max & Mean & Std.Dev \\
\hline HACQBC1 & $\begin{array}{l}\text { Hình ảnh cơ quan báo chí thể hiện } \\
\text { là đơn vị có sự sáng tạo trong lĩnh } \\
\text { vực báo chí. }\end{array}$ & 508 & 1.0 & 5.0 & 3.831 & .8719 \\
\hline HACQBC2 & $\begin{array}{l}\text { Hình ảnh cơ quan báo chí thể hiện } \\
\text { là đơn vị có tính tiên phong trong } \\
\text { lĩnh vực báo chí. }\end{array}$ & 508 & 1.0 & 5.0 & 3.823 & .8520 \\
\hline HACQBC3 & $\begin{array}{l}\text { Hình ảnh cơ quan báo chí thể hiện } \\
\text { là đơn vị có sự thành công trong } \\
\text { lînh vực báo chí. }\end{array}$ & 508 & 1.0 & 5.0 & 3.783 & .8795 \\
\hline HACQBC4 & $\begin{array}{l}\text { Hình ảnh cơ quan báo chí thể hiện } \\
\text { là đơn vị có sự tự tin trong lĩnh } \\
\text { vực báo chí. }\end{array}$ & 508 & 1.0 & 5.0 & 3.874 & .8402 \\
\hline HACQBC5 & $\begin{array}{l}\text { Hình ảnh cơ quan báo chí thể hiện } \\
\text { là đơn vị có sự trung thực, nhân } \\
\text { văn trong lĩnh vực báo chí. }\end{array}$ & 508 & 1.0 & 5.0 & 3.707 & .9476 \\
\hline HACQBC6 & $\begin{array}{l}\text { Hình ảnh cơ quan báo chí thể hiện } \\
\text { là đơn vị có sự cởi mở với bạn } \\
\text { đọc. }\end{array}$ & 508 & 1.0 & 5.0 & 3.679 & .8733 \\
\hline
\end{tabular}




\begin{tabular}{|l|l|c|c|c|c|c|}
\hline Ký hiệu & Các biến quan sát & $\mathbf{N}$ & Min & Max & Mean & Std.Dev \\
\hline HACQBC7 & $\begin{array}{l}\text { Hình ảnh cơ quân báo chí thể hiện } \\
\text { là đơn vị luôn săn sàng phản hồi } \\
\text { với bạn đọc. }\end{array}$ & 508 & 1.0 & 5.0 & 3.624 & .9028 \\
\hline HACQBC8 & $\begin{array}{l}\text { Hình ảnh cơ quan báo chí thể hiện } \\
\text { đó có phải là đơn vị có trách } \\
\text { nhiệm với xã hội hay không. }\end{array}$ & 508 & 1.0 & 5.0 & 3.764 & .9033 \\
\hline HACQBC9 & $\begin{array}{l}\text { Hình ảnh cơ quan báo chí thể hiện } \\
\text { là đơn vị tin cậy để người dân } \\
\text { phản ánh những điều tốt và chưa } \\
\text { tốt của cuộc sống. }\end{array}$ & 508 & 1.0 & 5.0 & 3.917 & .7596 \\
\hline
\end{tabular}

Nguồn: Kết quả xử lý từ dữ liệu điều tra

"Hình ảnh cơ quan báo chí thể hiện là đơn vị tin cậy để người dân phản ánh những điều tốt và chưa tốt của cuộc sống" (HACQBC9) được đánh giá cao nhất, với giá trị trung bình là 3.917. Biến 'Hình ảnh cơ quan báo chí thể hiện là đơn vị luôn sẵn sàng phản hồi với bạn đọc.' (HACQBC7) có giá trị trung bình thấp nhất là 3.624. Nhìn chung, các biến quan sát trong nhân tố này không được đánh giá cao, không có biến quan sát nào có giá trị trung bình trên 4.

\section{Về Danh tiếng cơ quan (tổ chức) báo chí (DTCQBC)}

\section{Bảng 4}

Kết quả thống kê về danh tiếng cơ quan báo chí

\begin{tabular}{|c|l|c|c|c|c|c|}
\hline Ký hiệu & \multicolumn{1}{|c|}{ Các biến quan sát } & N & Min & Max & Mean & Std.Dev \\
\hline DTCQBC1 & $\begin{array}{l}\text { Cơ quan báo chí tạo ra các sản } \\
\text { phấm báo chí có sức hấp dẫn đối } \\
\text { với bạn đọc. }\end{array}$ & 508 & 1.0 & 5.0 & 3.996 & .8116 \\
\hline DTCQBC2 & $\begin{array}{l}\text { Cơ quan báo chí tạo ra các sản } \\
\text { phấm báo chí có trách nhiệm với } \\
\text { xã hội. }\end{array}$ & 508 & 1.0 & 5.0 & 4.116 & .7694 \\
\hline DTCQBC3 & $\begin{array}{l}\text { Cơ quan báo chí tạo ra các sản } \\
\text { phẩm báo chí có chất lượng tốt } \\
\text { (hay, đúng, nhanh, nhân văn) được } \\
\text { bạn đọc đánh giá cao. }\end{array}$ & 508 & 1.0 & 5.0 & 3.982 & .8366 \\
\hline DTCQBC4 & $\begin{array}{l}\text { Cơ quan báo chí tạo ra sản phẩm } \\
\text { báo chí có tính đi đầu, đột phá } \\
\text { trong lĩnh vực báo chí, được xã hội } \\
\text { ghi nhận. }\end{array}$ & 508 & 1.0 & 5.0 & 4.069 & .7802 \\
\hline DTCQBC5 & $\begin{array}{l}\text { Cơ quan báo chí tạo ra sản phẩm } \\
\text { báo chí có tính chiến đấu cao, đấu } \\
\text { tranh chống tiêu cực có hiệu quả. }\end{array}$ & 508 & 1.0 & 5.0 & 4.030 & .7902 \\
\hline
\end{tabular}




\begin{tabular}{|c|l|c|c|c|c|c|}
\hline Ký hiệu & \multicolumn{1}{|c|}{ Các biến quan sát } & N & Min & Max & Mean & Std.Dev \\
\hline DTCQBC6 & $\begin{array}{l}\text { Cơ quan báo chí tham gia tích cực } \\
\text { các hoạt động từ thiện-xã hội; cứu } \\
\text { trợ nạn nhần thiên tai, giúp đỡ } \\
\text { người nghèo. }\end{array}$ & 508 & 1.0 & 5.0 & 4.018 & .8054 \\
\hline DTCQBC7 & $\begin{array}{l}\text { Môi trường làm việc trong cơ quan } \\
\text { báo chí tốt. }\end{array}$ & 508 & 2.0 & 5.0 & 4.026 & .7170 \\
\hline DTCQBC8 & $\begin{array}{l}\text { Tình hình tài chính trong cơ quan } \\
\text { báo chí tốt. }\end{array}$ & 508 & 1.0 & 5.0 & 3.537 & .8930 \\
\hline DTCQBC9 & $\begin{array}{l}\text { Cơ quan báo chí thực hiện đúng } \\
\text { tôn chỉ, mục đích, chức năng, } \\
\text { nhiệm vụ được giao. }\end{array}$ & 508 & 1.0 & 5.0 & 4.134 & .7283 \\
\hline DTCQBC10 & $\begin{array}{l}\text { Cơ quan báo chí đáp ứng nhu cầu } \\
\text { thông tin của bạn đọc. }\end{array}$ & 508 & 1.0 & 5.0 & 3.795 & .7546 \\
\hline
\end{tabular}

Nguồn: Kết quả xử lý từ dữ liệu điều tra

Biến "Cơ quan báo chí thực hiện đúng tôn chỉ, mục đích, chức năng, nhiệm vụ được giao" (DTCQBC9) có giá trị trung bình cao nhất là 4.134. Biến 'Tình hình tài chính trong cơ quan báo chí tốt' (DTCQBC8) có giá trị trung bình thấp nhất là 3.537.

\section{Về Sụ cam kết/lòng trung thành của cơ quan báo chí (CK)}

\section{Bảng 5}

Kết quả thống kê về sự cam kết/lòng trung thành của cơ quan báo chí

\begin{tabular}{|c|c|c|c|c|c|c|}
\hline Ký hiệu & Các biến quan sát & $\mathbf{N}$ & Min & Max & Mean & Std.Dev \\
\hline CK1 & $\begin{array}{l}\text { Cơ quan báo chí luôn có trách nhiệm } \\
\text { với các sản phẩm báo chí và những } \\
\text { người tạo ra sản phẩm báo chí đó. }\end{array}$ & 508 & 1.0 & 5.0 & 4.181 & 6985 \\
\hline CK2 & $\begin{array}{l}\text { Cơ quan báo chí của tôi làm ra những } \\
\text { sản phẩm báo chí có chất lượng vượt } \\
\text { trội so với các cơ quan báo chí khác. }\end{array}$ & 508 & 2.0 & 5.0 & 3.630 & .8594 \\
\hline CK3 & $\begin{array}{l}\text { Tôi có tình cảm với cơ quan báo chí } \\
\text { mà tôi đang làm việc. }\end{array}$ & 508 & 1.0 & 5.0 & 4.209 & .6936 \\
\hline CK4 & $\begin{array}{l}\text { Tôi đánh giá cao những sản phẩm báo } \\
\text { chí của cơ quan báo chí mà tôi đang } \\
\text { làm việc. }\end{array}$ & 508 & 1.0 & 5.0 & 3.919 & .7891 \\
\hline CK5 & $\begin{array}{l}\text { Tôi luôn đọc (hoặc nghe, xem) các } \\
\text { sản phẩm báo chí do cơ quan báo chí- } \\
\text { nơi tôi đang làm việc tạo ra. }\end{array}$ & 508 & 1.0 & 5.0 & 4.122 & .7330 \\
\hline CK6 & $\begin{array}{l}\text { Cơ quan báo chí tôi đang làm việc } \\
\text { làm tôt việc giúp đỡ, hỗ trợ các nhà } \\
\text { báo gặp tai nạn trong quá trình tác } \\
\text { nghiệp hoặc về hưu. }\end{array}$ & 508 & 1.0 & 5.0 & 3.925 & .7909 \\
\hline
\end{tabular}




\begin{tabular}{|c|l|c|c|c|c|c|}
\hline Ký hiệu & \multicolumn{1}{|c|}{ Các biến quan sát } & $\mathbf{N}$ & Min & Max & Mean & Std.Dev \\
\hline CK7 & $\begin{array}{l}\text { Cơ quan báo chí tôi đang làm việc } \\
\text { thường xuyên quan tâm, chăm lo đời } \\
\text { sống cán bộ, nhân viên. }\end{array}$ & 508 & 1.0 & 5.0 & 4.065 & .7678 \\
\hline
\end{tabular}

Nguồn: Kết quả xử lý từ dữ liệu điều tra

Biến "Tôi có tình cảm với cơ quan báo chí mà tôi đang làm việc" (CK3) được đánh giá cao nhất với giá trị trung bình là 4.209; Biến 'Cơ quan báo chí của tôi làm ra những sản phẩm báo chí có chất lượng vượt trội so với các cơ quan báo chí khác.' (CK2) có giá trị trung bình thấp nhất là 3.630.

\subsection{Phân tích Cronbach's Alpha và EFA}

\subsubsection{Phân tích Cronbach's Alpha}

Kết quả tóm tắt phân tích độ tin cậy của từng nhân tố được thể hiện trong bảng sau:

\section{Bảng 6}

Tóm tắt kết quả phân tích Cronbach’s Alpha

\begin{tabular}{|l|c|c|l|}
\hline \multicolumn{1}{|c|}{ Nhân tố } & $\begin{array}{c}\text { Hệ số Cronbach' } \\
\text { Alpha }\end{array}$ & $\begin{array}{c}\text { Biến loại } \\
\text { bỏ }\end{array}$ & \multicolumn{1}{c|}{ Biến giữ lại } \\
\hline THCN & 0.822 & & $\begin{array}{l}\text { THCN1, THCN2, THCN3, THCN4, } \\
\text { THCN5, THCN6, THCN7, THCN8 }\end{array}$ \\
\hline TCQBC & 0.821 & & $\begin{array}{l}\text { TCQBC1, TCQBC2, TCQBC3, TCQBC4, } \\
\text { TCQBC5 }\end{array}$ \\
\hline HACQBC & 0.936 & $\begin{array}{l}\text { HACQBC1, HACQBC2, HACQBC3, } \\
\text { HACQBC4, HACQBC5, HACQBC6, } \\
\text { HACQBC7, HACQBC8, HACQBC9 }\end{array}$ \\
\hline DTCQBC & 0.892 & DTCQBC8 & $\begin{array}{l}\text { DTCQBC1, DTCQBC2, DTCQBC3, } \\
\text { DTCQBC4, DTCQBC5, DTCQBC6, } \\
\text { DTCQBC7, DTCQBC9, DTCQBC10 }\end{array}$ \\
\hline CK & 0.865 & & CK1, CK2, CK3, CK4, CK5, CK6, CK7 \\
\hline
\end{tabular}

Nguồn: Kết quả xử lý từ dữ liệu điều tra

Hệ số Cronbach's Alpha của các nhân tố: THCN, TCQBC, HACQBC, DTCQBC, CK đều >0.7. Biến DTCQBC8 bị loại.

\subsubsection{Phân tích nhân tố khám phá(EFA)}

\section{Bảng 7}

Tóm tắt một số thông số thống kê trong phân tích EFA

\begin{tabular}{|l|l|}
\hline Tham số thống kê & Giá trị thống kê \\
\hline Kaiser-Meyer-Olkin & 0.933 \\
\hline Kiềm định Bartlett's & 0.000 \\
\hline Giá trị riêng của nhân tố thứ 5 & 1.017 \\
\hline
\end{tabular}




\begin{tabular}{|l|l|}
\hline Tham số thống kê & Giá trị thống kê \\
\hline Tồng phương sai trích của 5 nhân tố & $64.860 \%$ \\
\hline
\end{tabular}

Nguồn: Kết quả phân tích dữ liệu của nhóm nghiên cứu

\section{Bảng 8}

Kết quả phân tích EFA lần cuối cho các biến độc lập

\begin{tabular}{|c|c|c|c|c|}
\hline & \multicolumn{4}{|c|}{ Nhân tố } \\
\hline & 1 & 2 & 3 & 4 \\
\hline HACQBC6 & .835 & & & \\
\hline HACQBC5 & .821 & & & \\
\hline HACQBC7 & .785 & & & \\
\hline HACQBC3 & .756 & & & \\
\hline HACQBC4 & .709 & & & \\
\hline HACQBC2 & .698 & & & \\
\hline DTCQBC3 & & .815 & & \\
\hline DTCQBC4 & & .801 & & \\
\hline DTCQBC2 & & .797 & & \\
\hline DTCQBC5 & & .737 & & \\
\hline DTCQBC1 & & .703 & & \\
\hline CK7 & & & .820 & \\
\hline CK6 & & & .769 & \\
\hline CK3 & & & .749 & \\
\hline DTCQBC7 & & & .587 & \\
\hline TCQBC3 & & & & .755 \\
\hline TCQBC1 & & & & .755 \\
\hline TCQBC2 & & & & .678 \\
\hline TCQBC4 & & & & .614 \\
\hline & $\begin{array}{l}\mathrm{D}=0 \\
\text { alue }\end{array}$ & $\begin{array}{ll}\mathrm{nh} \\
\mathrm{hg}\end{array}$ & $\begin{array}{l}\mathrm{g} .=0 \\
=67\end{array}$ & \\
\hline
\end{tabular}

Nguồn: Kết quả phân tích dữ liệu của nhóm nghiên cứu

\subsection{Phân tích Mô hình cấu trúc (SEM)}

Kết quả từ Mô hình cấu trúc như sau:

\section{Bảng 9}

Trọng số hồi quy

\begin{tabular}{|l|l|l|r|r|r|r|r|r|}
\hline & & & \multicolumn{2}{|c|}{ Hệ số } & & & & \\
\hline & & $\begin{array}{c}\text { Chưa } \\
\text { chuẩn hóa }\end{array}$ & $\begin{array}{c}\text { Chuẩn } \\
\text { hóa }\end{array}$ & $\begin{array}{l}\text { Sai số } \\
\text { chuấn }\end{array}$ & C.R. & P-value & \\
\hline $\begin{array}{l}\text { hinh anh } \\
\text { CQBC }\end{array}$ & $<--$ & $\begin{array}{l}\text { ten co quan } \\
\text { bao chi }\end{array}$ & $0.715^{* * *}$ & 0.59 & 0.043 & 16.446 & 0.000 & $<0.01$ \\
\hline
\end{tabular}




\begin{tabular}{|c|c|c|c|c|c|c|c|c|}
\hline & & & \multicolumn{2}{|c|}{ Hệ số } & \multirow[b]{2}{*}{$\begin{array}{l}\text { Sai số } \\
\text { chuẩn }\end{array}$} & \multirow[b]{2}{*}{ C.R. } & \multirow[b]{2}{*}{ P-value } & \\
\hline & & & $\begin{array}{c}\text { Chưa } \\
\text { chuẩn hóa }\end{array}$ & $\begin{array}{c}\text { Chuẩn } \\
\text { hóa }\end{array}$ & & & & \\
\hline $\begin{array}{l}\text { danh tieng } \\
\text { CQBC }\end{array}$ & $\begin{array}{l}<- \\
--\end{array}$ & $\begin{array}{l}\text { hinh anh } \\
\text { CQBC }\end{array}$ & $0.39 * * *$ & 0.43 & 0.038 & 10.323 & 0.000 & \\
\hline $\begin{array}{l}\text { danh tieng } \\
\text { CQBC }\end{array}$ & $\begin{array}{l}<- \\
--\end{array}$ & $\begin{array}{l}\text { ten co quan } \\
\text { bao chi }\end{array}$ & $0.327 * * *$ & 0.298 & 0.046 & 7.145 & 0.000 & \\
\hline $\begin{array}{l}\text { su cam ket } \\
\text { cua CQBC }\end{array}$ & $\begin{array}{l}<- \\
--\end{array}$ & $\begin{array}{l}\text { hinh anh } \\
\text { CQBC }\end{array}$ & $0.203 * * *$ & 0.243 & 0.045 & 4.489 & 0.000 & \\
\hline $\begin{array}{l}\text { su cam ket } \\
\text { cua CQBC }\end{array}$ & $\begin{array}{l}<- \\
--\end{array}$ & $\begin{array}{l}\text { danh tieng } \\
\text { CQBC }\end{array}$ & $0.226 * * *$ & 0.246 & 0.048 & 4.686 & 0.000 & \\
\hline $\begin{array}{l}\text { su cam ket } \\
\text { cua CQBC }\end{array}$ & $\begin{array}{l}<- \\
--\end{array}$ & $\begin{array}{l}\text { ten co quan } \\
\text { bao chi }\end{array}$ & 0.009 & 0.009 & 0.052 & 0.179 & 0.858 & $>0.1$ \\
\hline $\begin{array}{l}\text { thuong } \\
\text { hieu ca } \\
\text { nhan }\end{array}$ & $\begin{array}{l}<- \\
--\end{array}$ & $\begin{array}{l}\text { su cam ket } \\
\text { cua CQBC }\end{array}$ & $0.234 * * *$ & 0.254 & 0.042 & 5.553 & 0.000 & \\
\hline $\begin{array}{l}\text { thuong } \\
\text { hieu ca } \\
\text { nhan }\end{array}$ & $\begin{array}{l}<- \\
--\end{array}$ & $\begin{array}{l}\text { ten co quan } \\
\text { bao chi }\end{array}$ & 0.065 & 0.07 & 0.05 & 1.309 & 0.190 & $>0.1$ \\
\hline $\begin{array}{l}\text { thuong } \\
\text { hieu ca } \\
\text { nhan }\end{array}$ & $\begin{array}{l}<- \\
--\end{array}$ & $\begin{array}{l}\text { danh tieng } \\
\text { CQBC }\end{array}$ & $0.086^{*}$ & 0.102 & 0.047 & 1.846 & 0.065 & $<0.1$ \\
\hline $\begin{array}{l}\text { thuong } \\
\text { hieu ca } \\
\text { nhan }\end{array}$ & $\begin{array}{l}<- \\
--\end{array}$ & $\begin{array}{l}\text { hinh anh } \\
\text { CQBC }\end{array}$ & 0.053 & 0.069 & 0.044 & 1.216 & 0.224 & $>0.1$ \\
\hline
\end{tabular}

Nguồn: Kết quả phân tích dữ liệu của nhóm nghiên cứu

\section{Bảng 10}

Trọng số hồi quy chuẩn

Standardized Regression Weights:

\begin{tabular}{|l|l|l|r|}
\hline hinh anh CQBC & $<---$ & ten co quan bao chi & 0.59 \\
\hline danh tieng CQBC & $<---$ & hinh anh CQBC & 0.43 \\
\hline danh tieng CQBC & $<---$ & ten co quan bao chi & 0.298 \\
\hline su cam ket cua CQBC & $<---$ & hinh anh CQBC & 0.243 \\
\hline su cam ket cua CQBC & $<---$ & danh tieng CQBC & 0.246 \\
\hline su cam ket cua CQBC & $<---$ & ten co quan bao chi & 0.009 \\
\hline thuong hieu ca nhan & $<---$ & su cam ket cua CQBC & 0.254 \\
\hline thuong hieu ca nhan & $<---$ & ten co quan bao chi & 0.07 \\
\hline thuong hieu ca nhan & $<---$ & danh tieng CQBC & 0.102 \\
\hline thuong hieu ca nhan & $<---$ & hinh anh CQBC & 0.069 \\
\hline
\end{tabular}

Nguồn: Kết quả phân tích dữ liệu của nhóm nghiên cứu 


\section{Bảng 11}

Các chỉ số FIT của mô hình SEM

\begin{tabular}{|l|c|}
\hline Chi-square/df (cmin/df) & 2.763 \\
\hline CFI & .986 \\
\hline GFI & .967 \\
\hline TLI & .970 \\
\hline RMSEA & .047 \\
\hline PCLOSE & .058 \\
\hline
\end{tabular}

Nguồn: Kết quả phân tích dữ liệu của nhóm nghiên cứu

\subsection{Thảo luận kết quả tù̀ Mô hình cấu trúc}

Kiểm định mô hình nghiên cứu (Path Analysis):

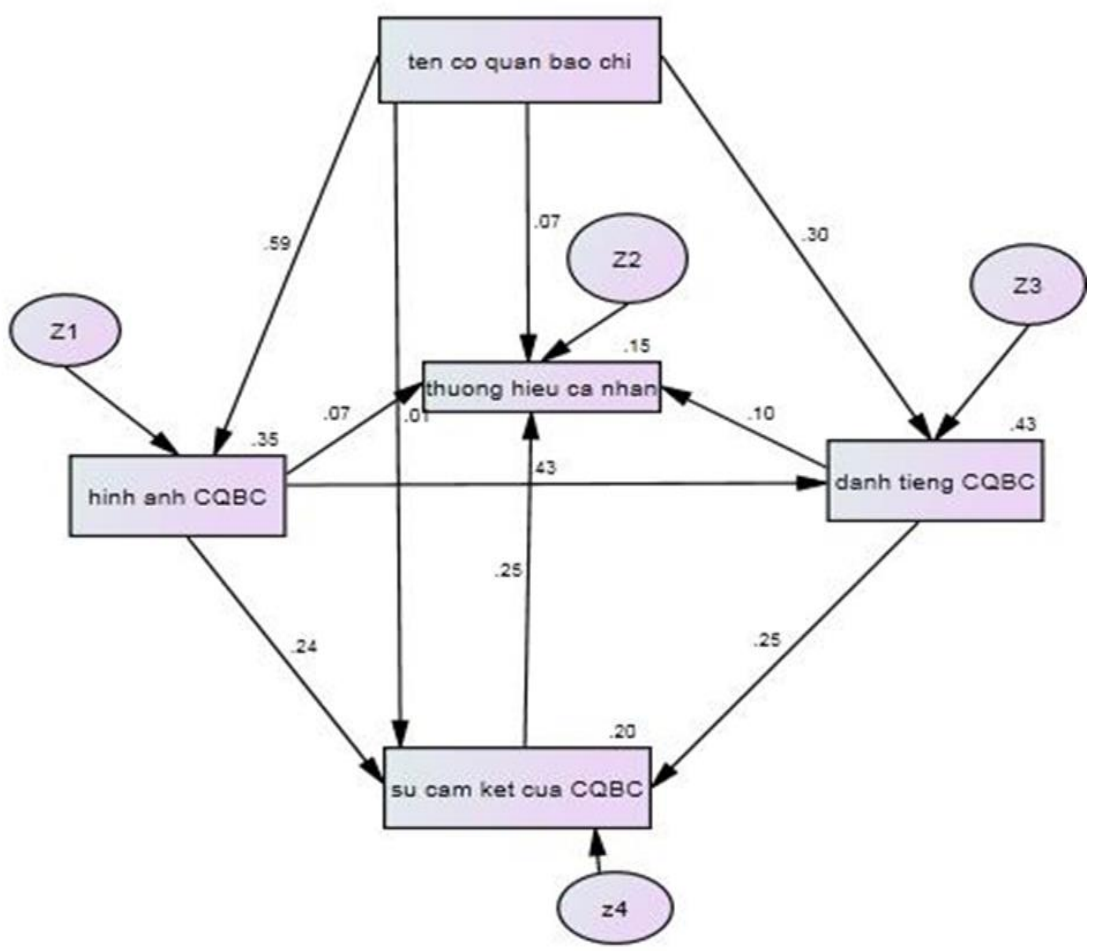

Hình 2. Mô hình nghiên cứu về mối quan hệ giữa THTC và THCN (Path Analysis)

Kết quả ki ểm định mô hình nghiên c ứu được thực hiện bởi kỹ thuật Path Analysis vì mô hình có biến trung gian (có nhiều biến phụ thuộc, các biến phụ thuộc này ảnh hưởng đến biến phụ thuộc khác).

(H1)

Tên cơ quan báo chí ảnh hưởng đến Thương hiệu cá nhân trong lĩnh vục báo chí

Kết quả nghiên cứu cho thấy: hệ số chưa chuẩn hóa là 0.065 , hệ số chuẩn hóa $=0.07$, hệ số C.R.=1.309. Biến này có $\mathrm{P}$-value $=0.190$, không có ý nghĩa thống kê nên không chấp nhận 
giả thuyết H1. Tức là, tên cơ quan báo chí không ảnh hưởng đến thương hiệu cá nhân trong lĩnh vực báo chí.

So với kết quả nghiên cứu trước của Schawbel (2010), kết quả của nghiên cứu này có điểm khác do đặc trưng của lĩnh vực báo chí ở Việt Nam. Schawbel (2010) cho rằng, Tên của cơ quan, đơn vị nào đó có ảnh hưởng, tác động đến Thương hiệu cá nhân của những người đang làm việc tại đó, chẳng hạn những người đang làm việc cho Google, Facebook, Intel có giá trị thương hiệu cá nhân thường cao hơn những đồng nghiệp đang làm việc cùng cấp tại các công ty $\mathrm{X}, \mathrm{Y}, \mathrm{Z}$ nào đó. Tuy nhiên, trong lĩnh vực báo chí Việt Nam, do đặc thù riêng, mức độ nhận thức về thương hiệu tổ chức và thương hiệu cá nhân của nhiều nhà báo có sự phân tán nên kết quả nghiên cứu xác định tên cơ quan báo chí không ảnh hưởng đến thương hiệu cá nhân trong lĩnh vực báo chí.

\section{Tên cơ quan báo chí có ảnh hưởng đến Hình ảnh cơ quan báo chí (H2)}

Mối quan hệ giữa "tên co quan báo chi" và "hình ảnh co quan báo chi" có ý nghĩa thống kê ở mức ý nghĩa $1 \%(\mathrm{P}$-value $=0.000,<0,01)$; quan hệ này là thuận chiều (hệ số hồi quy $=0.715)$, nghĩa là nhiều người biết đến tên cơ quan báo chí nhiều thì hình ảnh của cơ quan báo chí được nhiều người biết đến. Như vậy, giả thuyết $\mathrm{H} 2$ được chấp nhận.

Mặc dù Tên của cơ quan báo chí tác động dương (+) lên Hình ảnh cơ quan báo chí, nhưng đó là bước đầu khi một người nghe/nhìn thấy Tên cơ quan báo chí và hình dung trong tâm trí về Hình ảnh cơ quan báo chí đó. Nhưng Hình ảnh cơ quan báo chí đó không phải là bất biến mà có thể thay đổi theo thời gian hoặc qua những sự kiện/vấn đề mà cơ quan báo chí đó phản ánh, thông tin, đánh giá. Có trường hợp, ban đầu Tên cơ quan báo chí tạo ra Hình ảnh cơ quan báo chí trong tâm trí mọi người rất tích cực nhưng qua một thời gian, với các hoạt động thực tế không mang lại hiệu quả tốt cho xã hội, mặc dù Tên cơ quan báo chí vẫn không thay đổi, nhưng Hình ảnh cơ quan báo chí đó trong tâm trí nhiều người bị giảm sút, có thể trở nên tiêu cực. Ngược lại, cũng có trường hợp, ban đầu Tên cơ quan báo chí tạo ra Hình ảnh cơ quan báo chí trong tâm trí mọi người không tích cực, nhưng qua hoạt động thực tế mang lại hiệu quả cao, được xã hội ghi nhận, mặc dù Tên cơ quan báo chí không thay đổi nhưng Hình ảnh cơ quan báo chí đó trong tâm trí của nhiều người thay đổi theo hướng tích cực.

Nếu Tên cơ quan báo chí được duy trì, phát triển tích cực sẽ góp phần làm tăng giá trị, sức lan tỏa của Hình ảnh cơ quan báo chí.

Kết quả nghiên cứu này phù hợp với kết quả nghiên cứu của Saraniemi và cộng sự (2010) về tầm quan trọng và sự tác động của Tên tổ chức đối với Hình ảnh và thương hiệu tổ chức. Nghiên cứu này xác định Tên cơ quan báo chí tác động dương đến Hình ảnh cơ quan báo chí, về bản chất là đúng với kết quả nghiên cứu của Saraniemi và cộng sự (2010).

Tên cơ quan báo chí là yếu tố đầu tiên, tác động nhanh nhất vào tâm trí mọi người, sau đó chuyển thành Hình ảnh cơ quan báo chí. Do đó, Tên cơ quan báo chí thường ngay lập tức tạo ra Hình ảnh cơ quan báo chí trong tâm trí bạn đọc. Hình ảnh cơ quan báo chí có thể là tích cực, năng động, sáng tạo hay tiêu cực, thụ động, thiếu sáng tạo, ... tùy thuộc một phần vào Tên cơ quan báo chí và những gì mà những con người đang làm việc trong cơ quan đó tạo ra. 


\section{Tên cơ quan báo chí ảnh hưởng đến Danh tiếng của cơ quan báo chí (H3)}

Kết quả nghiên cứu cho thấy mối quan hệ giữa "tên co quan báo chi” và "danh tiếng co quan báo chi" " có ý nghĩa thống kê ở mức ý nghĩa $1 \%(\mathrm{P}$-value $=0.000,<0,01)$; quan hệ này là thuận chiều (hệ số hồi quy=0.327), nghĩa là Tên cơ quan được biết nhiều thì Danh tiếng của cơ quan đó được nâng lên. Như vậy, giả thuyết $\mathrm{H} 3$ được chấp nhận.

Nghiên cứu này phù hợp với kết quả nghiên cứu của Ngo (2012) về thương hiệu báo chí vì xác định Tên cơ quan báo chí có tác động dương lên Danh tiếng cơ quan báo chí. Tên cơ quan báo chí được xem như một sự đảm bảo về danh tiếng. Khi Tên cơ quan báo chí xuất hiện trong tâm trí bạn đọc, hình ảnh và danh tiếng của cơ quan báo chí đó cũng sẽ xuất hiện trong tâm trí của họ, giúp họ xác định mức độ nổi tiếng để có sự tiếp cận, đánh giá phù hợp. Danh tiếng cơ quan báo chí càng lớn thì độ tin cậy của bạn đọc càng cao, nhờ đó, sức thu hút đối với bạn đọc cũng tăng lên.

\section{Tên cơ quan báo chí ảnh hưởng đến Sụ cam kết của cơ quan báo chí (H4)}

Mối quan hệ giữa "tên co quan báo chi”" và "sụ cam kết của $C Q B C$ ” có $\mathrm{P}$-value $=0.858$ với hệ số hồi quy= 0.009 , giả thuyết này không có ý nghĩa thống kê. Như vậy, giả thuyết H4 bị bác bỏ, tức là Tên cơ quan báo chí không tác động đến Sự cam kết của cơ quan báo chí.

Kết quả nghiên cứu này có điểm khác với nghiên cứu trước của Souiden và cộng sự (2006), Cretu và Brodie (2005) do đặc thù của lĩnh vực báo chí tại Việt Nam. Các nghiên cứu của Souiden và cộng sự (2006), Cretu và Brodie (2005) chủ yếu tập trung vào mối quan hệ giữa Tên các doanh nghiệp, tập đoàn và Sự cam kết/lòng trung thành của nhân viên, khách hàng đối với các doanh nghiệp, tập đoàn đó. Trong đó, Souiden và cộng sự (2006), Cretu và Brodie (2005) cho rằng Tên công ty, tập đoàn có tác động dương (+) lên Sự cam kết/lòng trung thành của nhân viên, khách hàng đối với các doanh nghiệp, tập đoàn đó. Còn nghiên cứu này nghiên cứu về mối quan hệ giữa Tên của cơ quan báo chí và Sự cam kết của cơ quan báo chí đối với quyền lợi của nhân viên (là một trong những điểm mới của nghiên cứu này) trong lĩnh vực báo chí tại Việt Nam. Kết quả nghiên cứu cho thấy Tên cơ quan báo chí không tác động đến Sự cam kết của cơ quan báo chí đối với quyền lợi của nhân viên.

Hình ảnh cơ quan báo chí ảnh hưởng đến Thuơng hiệu cá nhân của các nhà báo

Mối quan hệ giữa "hình ảnh co' quan báo chi”" và "thưong hiệu cá nhân" có Pvalue=0.224 nên không có ý nghĩa thống kê. Giả thuyết H5 không được chấp nhận, tức là Hình ảnh cơ quan báo chí không ảnh hưởng đến Thương hiệu cá nhân của các nhà báo.

Kết quả của nghiên cứu này có điểm khác với nghiên cứu của Schawbel (2010). Schawbel nghiên cứu về sự tác động của Hình ảnh tổ chức nói chung (như công ty, tập đoàn, tổ chức truyền thông, ...) đối với Thương hiệu cá nhân (gồm: lãnh đạo doanh nghiệp, tập đoàn, lãnh đạo tổ chức truyền thông,...). Kết quả nghiên cứu của Schawbel là Hình ảnh tổ chức tác động lên Thương hiệu cá nhân. Trong khi đó, nghiên cứu này tập trung nghiên cứu về sự tác động của Hình ảnh cơ quan báo chí lên Thương hiệu cá nhân nhà báo. Kết quả của nghiên cứu này xác định Hình ảnh cơ quan báo chí không có tác động lên Thương hiệu cá nhân là phù hợp với đặc thù của nền báo chí cách mạng Việt Nam. 


\section{Hình ảnh cơ quan báo chí ảnh hưởng đến Danh tiếng cơ quan báo chí (H6)}

Mối quan hệ giữa "hình ảnh $C Q B C$ ” và "danh tiếng co quan báo chi” có ý nghĩa thống kê ở mức ý nghĩa $1 \%(\mathrm{P}$-value= $0.000,<0,01)$; quan hệ này là thuận chiều (hệ số hồi quy=0.39), nghĩa là hình ảnh cơ quan báo chí càng lớn thì danh tiếng của cơ quan đó càng nhiều. Như vậy, giả thuyết H6 được chấp nhận.

Kết quả này phù hợp với kết quả nghiên cứu của Souiden và cộng sự (2006), Pina và Martinez (2006) vì đều có xác định mối quan hệ giữa Hình ảnh tổ chức và Danh tiếng tổ chức trong thương hiệu. Các nghiên cứu của Souiden và cộng sự (2006), Pina và Martinez (2006) đều cho rằng, Hình ảnh tổ chức và Danh tiếng tổ chức có mối quan hệ chặt chẽ với nhau, trong đó Hình ảnh tổ chức tác động lên Danh tiếng tổ chức, làm tăng giá trị của thương hiệu tổ chức. Kết quả nghiên cứu định lượng của nghiên cứu này có đầy đủ các yếu tố để kết luận: Hình ảnh cơ quan báo chí tác động dương (+) lên Danh tiếng cơ quan báo chí.

\section{Hình ảnh cơ quan báo chí ảnh hưởng đến Sụ cam kết của cơ quan báo chí (H7)}

Mối quan hệ giữa "hình ảnh co quan báo chi” "và "sự cam kết của co quan báo chi”" có ý nghĩa thống kê ở mức ý nghĩa $1 \%(\mathrm{P}$-value $=0.000,<0,01)$; quan hệ này là thuận chiều (hệ số hồi quy $=0.203$ ), nghĩa là hình ảnh của cơ quan báo chí được nhiều người biết đến thì sự cam kết/lòng trung thành của cơ quan báo chí đó càng cao. Như vậy, giả thuyết $\mathrm{H} 7$ được chấp nhận.

Kết quả nghiên cứu này phù hợp với kết quả nghiên cứu trước của Cretu và Brodie (2005), Pina và Matinez (2006) vì xác định được Hình ảnh cơ quan/tổ chức tác động dương (+) lên Sự cam kết của cơ quan/tổ chức đối với quyền lợi của nhân viên. Các nghiên cứu trước của Cretu và Brodie (2005), Pina và Matinez (2006) chỉ nghiên cứu chung về Hình ảnh cơ quan/tổ chức và Sự cam kết của cơ quan/tổ chức đối với nhân viên. Còn nghiên cứu này nghiên cứu về mối quan hệ giữa Hình ảnh cơ quan báo chí và Sự cam kết của cơ quan báo chí đối với quyền lợi của nhân viên. Tuy nhiên, nghiên cứu này và các nghiên cứu trước đều xác định được mối quan hệ giữa Hình ảnh tổ chức và Sự cam kết của tổ chức, trong đó Hình ảnh tổ chức (cơ quan báo chí) tác động lên Sự cam kết của tổ chức (cơ quan báo chí).

\section{Danh tiếng của cơ quan báo chí ảnh hương đến Thưong hiệu cá nhân trong lĩnh vục} báo chí (H8)

Mối quan hệ giữa "danh tiếng $C Q B C$ ” và "thưong hiệu cá nhân” có Pvalue $=0.065<0.1$, hệ số hồi quy= 0.086 cho thấy đây là quan hệ thuận chiều, nghĩa là danh tiếng của cơ quan báo chí càng lớn thì những người làm trong cơ quan báo chí đó càng có thương hiệu (uy tín). Như vậy, giả thuyết H8 được chấp nhận.

So với các kết quả nghiên cứu trước của Schawbel (2010), Souiden và cộng sự (2006), kết quả nghiên cứu này là phù hợp vì xác định được Danh tiếng cơ quan báo chí tác động dương (+) lên Thương hiệu cá nhân các nhà báo đang làm việc tại cơ quan báo chí đó. Các nghiên cứu của Schawbel (2010), Souiden và cộng sự (2006) đều cho rằng, Danh tiếng của tổ chức tác động lên Thương hiệu cá nhân của những người làm việc trong tổ chức đó. Ví dụ: Những tổ chức như: Ngân hàng Thế giới (WB), Tổ chức Tài chính Thế giới (IFC), Liên Hiệp quốc (UN), ... đều là các tổ chức có danh tiếng toàn cầu. Do đó, giá trị thương hiệu cá nhân của những người làm việc trong các tổ chức này được nâng cao hơn so với những người làm việc trong các tổ 
chức ít danh tiếng hơn. Nghiên cứu này tập trung vào Danh tiếng cơ quan báo chí và Thương hiệu cá nhân nhà báo, nhưng kết quả cũng tương tự. Ví dụ: Những nhà báo làm việc trong các tập đoàn, tổ chức truyền thông lớn như: $\mathrm{CNN}, \mathrm{BBC}, \mathrm{VTV}, \mathrm{VOV}, \ldots$ thường có giá trị thương hiệu cá nhân cao hơn những nhà báo làm việc trong các tổ chức, cơ quan báo chí quy mô nhỏ, ít danh tiếng.

Danh tiếng của cơ quan báo chí ảnh hưởng đến Sục cam kết của cơ quan báo chí đối với quyền lọi của nhân viên (H9)

Mối quan hệ giữa "danh tiếng co quan báo chi" và "sụ cam kết của cơ quan báo chi" có ý nghĩa thống kê ở mức ý nghĩa $1 \%$ (P-value $=0.000,<0,01)$; quan hệ này là thuận chiều (hệ số hồi quy=0.226). Biến "danh tiếng co quan báo chi" tác động dương (+) lên "sư cam kết của co quan báo chi”, nghĩa là danh tiếng của cơ quan báo chí càng lớn thì sự cam kết của cơ quan đó càng cao. Như vậy, giả thuyết H9 được chấp nhận.

So với các nghiên cứu trước của Pina và Matinez (2006), Souiden và cộng sự (2006), kết quả nghiên cứu này là phù hợp vì xác định được Danh tiếng cơ quan báo chí tác động lên Sự cam kết của cơ quan báo chí. Các nghiên cứu trước của Pina và Matinez (2006), Souiden và cộng sự (2006) nghiên cứu về mối quan hệ giữa Danh tiếng tổ chức và Sự cam kết của tổ chức, trong đó xác định Danh tiếng tổ chức có tác động dương lên Sự cam kết của tổ chức. Nghiên cứu này nghiên cứu về mối quan hệ giữa Danh tiếng cơ quan báo chí và Sự cam kết của cơ quan báo chí, trong đó xác định Danh tiếng cơ quan báo chí có tác động dương (+) lên Sự cam kết của cơ quan báo chí, đều đó có nghĩa là những cơ quan báo chí nào càng có danh tiếng thì càng đảm bảo sự cam kết đối với quyền lợi của nhân viên. Mặc dù trong những giai đoạn khó khăn, sự thực hiện các cam kết này có thể bị ảnh hưởng nhưng nhìn chung các cơ quan báo chí có danh tiếng đều đảm bảo sự cam kết với nhân viên.

Sự cam kết của cơ quan báo chí đối với quyền lọi của nhân viên ảnh hưởng đến Thuơng hiệu cá nhân nhà báo (H10)

Mối quan hệ giữa "sư cam kết của cơ quan báo chî" và "thuoong hiệu cá nhân" có ý nghĩa thống kê ở mức ý nghĩa $1 \%$ (P-value $=0.000,<0.01$ ); quan hệ này là thuận chiều (hệ số hồi quy=0.234). Biến "sự cam kết của cơ quan báo chi" tác động dương (+) lên "thương hiệu cá nhân", nghĩa là Sự cam kết của cơ quan báo chí đối với quyền lợi của nhân viên càng chắc chắn thì Thương hiệu cá nhân của nhân viên trong cơ quan báo chí càng lớn. Như vậy, giả thuyết H10 được chấp nhận.

So với các nghiên cứu trước của Schawbel (2010), kết quả nghiên cứu này là hợp lý vì đã xác định được Sự cam kết của cơ quan báo chí tác động lên Thương hiệu cá nhân trong lĩnh vực báo chí. Bất cứ cá nhân nhà báo nào khi được làm việc trong các cơ quan báo chí có sự cam kết với nhân viên cũng đều hãnh diện và yên tâm công tác. Nghề báo vốn là nghề nhiều rủi ro, nguy hiểm, do đó những người làm báo cần có một chỗ dựa vững chắc về vật chất lẫn tinh thần cho bản thân và gia đình của họ. Các đồng nghiệp báo chí khi đánh giá lẫn nhau cũng nhìn nhận đồng nghiệp của mình đang làm việc tại một cơ quan đảm bảo hay không đảm bảo sự cam kết với nhân viên về quyền lợi. 
Tóm lại, các giả thuyết trong mối quan hệ giữa thương hiệu tổ chức và thương hiệu cá nhân trong lĩnh vực báo chí được kiểm định như sau:

\section{Bảng 12}

Kết quả tổng hợp các giả thuyết được kiểm định

\begin{tabular}{|c|c|c|}
\hline & Giả thuyết & Kết quả \\
\hline$H 1$ & $\begin{array}{l}\text { Tên co quan báo chí có ảnh hương duoong (+) đến thưong hiệu } \\
\text { cá nhân của nhũng nhà báo đang làm việc tại co quan đó }\end{array}$ & Bác bỏ \\
\hline$H 2$ & $\begin{array}{l}\text { Tên cơ quan báo chí có ảnh hưởng dương }(+) \text { đến Hình ảnh co } \\
\text { quan báo chí đó }\end{array}$ & Chấp nhận \\
\hline$H 3$ & $\begin{array}{l}\text { Tên cơ quan báo chí ảnh hưởng duơng (+) đến Danh tiếng của } \\
\text { cơ quan báo chí đó }\end{array}$ & Chấp nhận \\
\hline$H 4$ & $\begin{array}{l}\text { Tên co quan báo chí có ảnh hương dương (+) đến Sư cam kết } \\
\text { của co quan báo chi đó đối với quyền lợi nhân viên }\end{array}$ & Bác bỏ \\
\hline H5 & $\begin{array}{l}\text { Hình ảnh co quan báo chí có ảnh hương dương (+) đối với } \\
\text { Thurơng hiệu cá nhân của các nhà báo đang làm việc tại co quan } \\
\text { báo chí đó }\end{array}$ & Bác bỏ \\
\hline H6 & $\begin{array}{l}\text { Hình ảnh co quan báo chí có ảnh hương duơng (+) đến Danh } \\
\text { tiếng co quan báo chí đó }\end{array}$ & Chấp nhận \\
\hline$H 7$ & $\begin{array}{l}\text { Hình ảnh co quan báo chí có ảnh hường duơng (+) đến Sư cam } \\
\text { kết của co quan báo chí đó đối với quyền lợi của nhân viên }\end{array}$ & Chấp nhận \\
\hline$H 8$ & $\begin{array}{l}\text { Danh tiếng của cơ quan báo chí có ảnh hưởng dương (+) đến } \\
\text { Thurong hiệu cá nhân của nhũ̃ng nhà báo đang làm việc tại co } \\
\text { quan báo chí đó }\end{array}$ & Chấp nhận \\
\hline H9 & $\begin{array}{l}\text { Danh tiếng của cơ quan báo chí có ảnh hương duơng (+) đối } \\
\text { với Sư cam kết của co quan báo chí đó đối với quyền lợi của } \\
\text { nhân viên }\end{array}$ & Chấp nhận \\
\hline H10 & $\begin{array}{l}\text { Sư cam kết của co quan báo chí đối với quyền lợi của nhân viên } \\
\text { ảnh hưởng duoong (+) đến Thuơng hiệu cá nhân của nhũng nhà } \\
\text { báo đang làm việc tại cơ quan báo chí đó }\end{array}$ & Chấp nhận \\
\hline
\end{tabular}

Nguồn: Kết quả xử lý từ dữ liệu điều tra

\section{Kết luận và gọii ý chính sách}

\subsection{Kết luận}

Kết quả nghiên cứu đã xác định 4 thành phần chính của thương hiệu tổ chức là: Tên cơ quan (tổ chức) báo chí, Danh tiếng cơ quan (tổ chức) báo chí, Hình ảnh cơ quan (tổ chức) báo chí, Sự cam kết/lòng trung thành của cơ quan (tổ chức) báo chí đối với nhân viên. 
Mô hình nghiên cứu đề xuất ban đầu gồm 4 thành phần của thương hiệu tổ chức tác động đến thương hiệu cá nhân, bao gồm: Tên cơ quan (tổ chức) báo chí, Danh tiếng cơ quan (tổ chức) báo chí, Hình ảnh cơ quan (tổ chức) báo chí, Sự cam kết/lòng trung thành của cơ quan (tổ chức) báo chí đối với nhân viên. Các thành phần trong mô hình được đo lường bởi 39 biến quan sát.

Sau khi tiến hành đánh giá độ tin cậy của thang đo và thực hiện phân tích nhân tố khám phá (EFA) đối với từng biến quan sát đo lường các thành phần của thương hiệu tổ chức tác động đến thương hiệu cá nhân, mặc dù đã loại bỏ một số biến quan sát không đạt các tiêu chí kiểm định nhưng vẫn không làm thay đổi bản chất của từng thành phần, các biến quan sát vẫn được gom lại thành 05 nhóm yếu tố. Vì vậy, mô hình nghiên cứu ban đầu vẫn được giữ nguyên.

Đối với mô hình đo lường, các biến quan sát được tách thành 5 nhân tố, kết quả phân tích nhân tố đảm bảo hệ số tải nhân tố $>0.5$ về trị tuyệt đối; với mỗi biến quan sát chênh lệch giữa hệ số tải nhân tố lớn nhất và hệ số tải nhân tố bất kỳ $>0.3$. Do vậy, thang đo đo lường các khái niệm nghiên cứu là đạt được giá trị phân biệt và giá trị hội tụ. Ngoài ra, kết quả phân tích nhân tố là sử dụng được [tổng phương trích $=56.798 \%(>50 \%) ; \mathrm{KMO}=0.92(>0.5)$; kiểm định Bartlett $=0.000(<0.05)]$.

Kết quả nghiên cứu cho thấy: $i$ ) Tên cơ quan báo chí có ảnh hưởng dương $(+)$ đến Hình ảnh cơ quan báo chí, Danh tiếng của cơ quan báo chí; ii) Hình ảnh cơ quan báo chí có ảnh hưởng dương $(+)$ đến Danh tiếng cơ quan báo chí và Sự cam kết/lòng trung thành của cơ quan báo chí; iii) Danh tiếng của cơ quan báo chí có ảnh hưởng dương (+) đến Thương hiệu cá nhân của những nhà báo và Sự cam kết/lòng trung thành với nhân viên của cơ quan báo chí; iv) Sự cam kết/lòng trung thành của cơ quan báo chí ảnh hưởng dương (+) đến Thương hiệu cá nhân của nhà báo. Tuy nhiên, nghiên cứu cho thấy, Tên cơ quan báo chí không ảnh hưởng đến thương hiệu cá nhân của những nhà báo và Sự cam kết/lòng trung thành của cơ quan báo chí; Hình ảnh cơ quan báo chí không ảnh hưởng đến Thương hiệu cá nhân của các nhà báo.

\subsection{Gọi ý chính sách}

Thư nhất: Các cơ quan báo chí cần hợp tác với các nhà nghiên cứu, nhà khoa học trong lĩnh vực thương hiệu, tổ chức khảo sát, nghiên cứu để có sự đánh giá toàn diện, chính xác về các thành phần của thương hiệu tổ chức trong cơ quan. Đồng thời đánh giá về sự tác động của các thành phần đó đối với thương hiệu cá nhân như thế nào. Từ đó xây dựng một kế hoạch phát triển thương hiệu cá nhân cho các nhà báo đang làm việc tại cơ quan của mình.

Thứ hai: Theo kết quả nghiên cứu, thương hiệu tổ chức và thương hiệu cá nhân có mối quan hệ chặt chẽ, có sự tác động, hỗ trợ lẫn nhau. Do đó, các cơ quan báo chí cần có kế hoạch phát triển song song hai dạng thương hiệu này, không nên tách rời nhau.

Thư ba: Theo kết quả khảo sát, nhiều nhà báo chưa được đào tạo chuyên ngành báo chí. Do đó, các cơ quan báo chí cần tăng cường công tác đào tạo chuyên ngành báo chí cho đội ngũ nhà báo.

Thứ tu: Trước thực tế mạng xã hội ngày càng phát triển, tình trạng các thông tin xấu, độc hại đang ngày càng lan tràn trên mạng và gây tác hại xấu đến cộng đồng, xã hội, Nhà nước 
cần có chính sách, chiến lược phát triển thương hiệu báo chí cho các cơ quan báo chính thống để tạo ra một môi trường thông tin an toàn, tin cậy, hiệu quả.

Thú năm: Kết quả nghiên cứu cho thấy nhận thức về thương hiệu báo chí của nhiều nhà báo còn hạn chế. Do đó, các cơ quan báo chí cần nâng cao nhận thức cho các nhà báo về tầm quan trọng của thương hiệu báo chí trong bối cảnh sự cạnh tranh thông tin ngày càng gay gắt. Từ nhận thức sâu sắc đó, cùng với việc tổ chức khảo sát, nghiên cứu một cách bài bản, khoa học sẽ phát triển thương hiệu tốt hơn.

\section{Tài liệu tham khảo}

Abratt, R., \& Mofokeng, T. N. (2001). Development and management of corporate image in South Africa. European Journal of Marketing, 35(3), 368-386.

Bhattacharya, C. B., \& Sen, S. (2003). Consumer-company identification: A framework for understanding consumers' relationships with companies. Journal of Marketing, 67(2), 76-88.

Cretu, A., \& Brodie, R. (2005). The influence of brand image and company reputation where manufacturers market to small firms: A customer value perspective. Industrial Marketing Management, 36(2), 230-240.

Do, H. T. T. (2013). Xây dựng thương hiệu sản phẩm báo chí: Khái niệm, vai trò và các bước thục hiện [Branding journalism products: Concept, role and implementation steps]. Retrieved January 20, 2018, from http://daotao.vtv.vn/xay-dung-thuong-hieu-san-phambao-chi-khai-niem-vai-tro-va-cac-buoc-thuc-hien/

Druckenmiller, P. A. (2004). Reputation and the corporate brand. Corporate Reputation Review, 6(4), 368-374.

Fournier, S. (1998). Consumers and their brands: Developing relationship theory in consumer research. Journal of Consumer Research, 24(4), 343-373.

Gotsi, M., \& Wilson M. A. (2001). Corporate reputation: Seeking a definition. Corporate communications: An International Journal, 6(1), 24-30.

Gregory, J. G., \& Wiechmann, J. R. (1999). Marketing corporate image: The company as your number one product ( 2 nd ed.). Boston, MA: McGraw-Hill

Hankinson, G., \& Cowking, P. (1993). Branding in action: Cases and strategies for profitable brand management. New York, NY: McGraw-Hill.

Hatch, M. J., \& Schultz, M. (2003). Bringing the corporation into corporate branding. European Journal of Marketing, 37(7/8), 1041-1064.

Holton, E. A., \& Molyneux, L. (2015). Identity lost? The personal impact of brand journalism. Journalism, 18(2), 195-210.

Hsieh, M. (2002). Identifying brand image dimensionality and measuring the degree of brand globalisation: A cross-national study. International Marketing Review, 10(2), 46-67.

Kennedy, S. H. (1977). Nurturing corporate images. European Journal of Marketing, 11(3), 119-164. 
Ngo, N. B. (2012). Một số hình thức xây dụng thưong hiệu báo chí [Some forms of journalism branding]. Retrieved October 10, 2017, from https://ajc.hcma.vn/Pages/nghien-cuukhoa-hoc. aspx $?$ CateID $=679 \&$ ItemID $=3133$

Pina, J. M., \& Martinez, E. (2006). The effect of service brand extensions on corporate image: An empirical model. European Journal of Marketing, 40(1/2), 174-197.

Saraniemi, S., Juntunen, M., Niemelä, T., \& Tähtinen, J. (2010). Influencing the corporate brand equity of small firms. Paper presented at the 6th Thought Leaders of Brand Management Conference, Lugano, Switzerland.

Schawbel, D. (2009). Me 2.0: Build a powerful brand to achieve career success. New York, NY: Kaplan Books.

Schawbel, D. (2010). Me 2.0:4 steps to building your future. New York, NY: Diversion Books.

Schawbel, D. (2012). Thuoong hiệu cá nhân-TÔI 2.0 [Personal brand-ME 2.0] (H. N. Nguyen, Trans.). Ho Chi Minh, Vietnam: Nhà xuất bản Trẻ.

Shapiro, C. (1983). Premiums for high quality products as returns to reputations. The Quarterly Journal of Economics, 98(4/1), 659-679.

Souiden, N., Kassim, M. N., \& Heung-Ja, H. (2006). The effect of corporate branding dimensions on consumers' product evaluation: A cross-cultural analysis. European Journal of Marketing, 40(7/8), 825-845. 